Editorial

\title{
The opioid epidemic and human attrition
}

\section{Editorial}

About the problem with the opiate epidemic for some 25 years. The issue of opiates and their introduction into a Society through the general population can be seen throughout human history. Humans have involved with opiate receptors and with endogenous opiates over millions of years. During the evolution of the human species homeostatic physiologic mechanisms there has also been the evolution of plants that produce opiates, the poppy. The Poppy has he been around since the dawn of the agricultural age 10,000 BC.

In 1836 there, was the Chinese opium wars. At that time roughly, half of the Chinese population (some $300,000,000$ ) became addicted to opioids. As best as it can be told the problems and generations to subside. During the 1990s the medical and pharmaceutical industries developed and distributed higher potency opioids and in greater amounts then had previously been entered into the United States. The medical complex taught doctors to treat pain with opiates and at the pain persisted to use more opiates in order to effectively treat pain. One of the consequences of those actions has led to the current opioid crisis. Another problem has led to the alteration entry of pain and to the escalating death rate from overdoses.

Why is the death rate from opioids continuing to rise over so many years after the rise the problem has occurred? Multifactor all issues are involved with the opiate epidemic. Prevention, education, prescribing practices, prescribing indications, smuggling, distribution, and illicit drug sales are all areas that can be addressed. Perceptions are difficult to change. Generations have to pass prescribing habits have to change, patient expectations have to change. The target is now the medical profession, the pharmaceutical industry, and most unfortunately patients in pain and patients who've become dependent and addicted to the opioids.

\author{
Volume 5 Issue 3 - 2018 \\ Jerrold Rand \\ DASAM University, USA
}

Correspondence: Jerrold Rand, DASAM University, UCLA Rotating Intern Wadsworth Veteran's Administration Hospital, USA, Email jerrynrand@gmail.com

Received: May 29, 2018 | Published: June 08, 2018

What may not be clear is that the rising death rate from overdose is decreasing the population of people taking opiates. Hundreds of thousands of Americans are dying hey is years pass during this crisis. There is a thinning of the herd I'm Drug users and of patients going to see doctors. Unfortunately, it is this process that is difficult to analyze that may over generations Restore some equilibrium to the use of pain medication in the medical profession. With all the billions of dollars being spent on addiction treatment, pain management, complicated medical care, and vast government expenditures, what are we accomplished? Has anyone included the complications of ineffective medical care that has resulted from this epidemic. Are we so lost in investigating and correcting the causes of this problem that nobody has been looking for the solution? So, in the end the process of attrition maybe the most effective long term, solution of the opioid epidemic.

\section{Acknowledgements}

None.

\section{Conflict of interest}

The author declares there is no conflict of interest. 